\title{
Öğretmen Adaylarının Eğitim Fakültesindeki Hizmet Kalitesine Yönelik Memnuniyet Düzeyleri *
}

\section{Pre-Service Teachers' Satisfaction with Service Quality in Education Faculty}

\author{
Murat BORAN ${ }^{1}$ Tuğba YANPAR YELKEN ${ }^{2}$
}

• Geliş Tarihi: 28.01.2019 • Kabul Tarihi: 04.08.2019 • Çevrimiçi Yayın Tarihi: 04.08.2019

\section{$\ddot{O} \mathbf{z}$}

$\mathrm{Bu}$ çalışma, öğretmen adaylarının eğitim fakültesindeki hizmet kalitesine yönelik memnuniyet düzeylerini betimsel olarak incelemeyi amaçlamaktadır. Tarama modelinde gerçekleştirilen bu çalışmanın örneklemi, 2016-2017 eğitimöğretim yılında Mersin Üniversitesi Eğitim Fakültesi'nin farklı bölümlerinde okuyan 674 adet öğretmen adayından oluşmaktadır. Yapılan analizler sonucunda elde edilen bulgulara göre, öğretmen adaylarının eğitim fakültesindeki hizmet kalitesine yönelik memnuniyet düzeylerinin orta seviyede olduğu görülmüştür. Bununla birlikte, kadın ve erkek öğretmen adaylarının memnuniyet düzeyleri arasında erkek öğretmen adayları lehine istatistiksel olarak anlamlı farklılıklar tespit edilmiştir. Ayrıca eğitim fakültesinin hizmet kalitesinden en çok memnun olan öğretmen adayları, Bilgisayar ve Öğretim Teknolojileri Eğitimi (BÖTE) ve Türkçe Öğretimi bölümlerindenken, en az memnun olanları ise Okul Öncesi ve Sınıf Öğretmenliği bölümlerindendir.

Anahtar sözcükler: eğitim fakültesi, öğretmen adayı, hizmet kalitesi, memnuniyet.

Atıf:

Boran, M. ve Yapar Yelken, T. (2020). Öğretmen adaylarının eğitim fakültesindeki hizmet kalitesine yönelik memnuniyet düzeyleri. Pamukkale Üniversitesi Ĕ̈itim Fakültesi Dergisi, 48, 390-408. doi: $10.9779 /$ pauefd.518787.

\footnotetext{
* Bu çalıșma 19-21 Mayıs 2017 tarihlerinde İstanbul'da gerçekleşen Uluslararası Öğretmen Eğitimi ve Akreditasyon Kongresi'nde sözlü bildiri olarak sunulmuştur.

${ }^{1}$ Arş. Gör., Erciyes Üniversitesi, muratboran@erciyes.du.tr, Orcid ID: 0000-0003-4626-2404

${ }^{2}$ Prof. Dr., Mersin Üniversitesi, tyanpar@mersin.edu.tr, Orcid ID: 0000-0002-0800-4802
} 


\begin{abstract}
This study aims to investigate the pre-service teachers' levels of satisfaction with the service quality in the education faculty. This study was carried out in the survey model. Determined by using the convenience sampling method, the sample consisted of 674 pre-service teachers studying in different departments in the Education Faculty of Mersin University in the academic year of 2016-2017. According to the results, it was found that pre-service teachers' levels of satisfaction with the service quality in the education faculty were at an intermediate level. The results indicated that there were statistically significant differences between female and male pre-service teachers' satisfaction levels. The most satisfied pre-service teachers were from the departments of Computer Education and Instructional Technology (CEIT) and Turkish Language Teaching whereas the least satisfied were from the departments of Preschool and Primary School Teaching.
\end{abstract}

Keywords: education faculty, pre-service teachers, service quality, satisfaction.

\title{
Cited:
}

Boran, M. \& Yapar Yelken, T. (2020). Pre-service teachers' satisfaction with service quality in education faculty. Pamukkale Üniversitesi Ĕ̆itim Fakültesi Dergisi, 48, 390-408. doi:

10.9779/pauefd.518787. 


\section{Giriş}

Ülkelerin nitelikli insan kaynağının ve dolayısıyla ekonomisinin gelişiminde önemli bir rol oynayan yükseköğretim kurumları, küreselleşen dünyadaki artan küresel rekabetten etkilenerek ikinci kuşak olarak kabul edilen bilim temelli üniversitelerden girişimci üniversite ya da multiversite olarak isimlendirilen üçüncü kuşak üniversitelere doğru bir geçiş yapmaktadır (Kaur ve Bhalla, 2018; Wissema, 2009, Akt: Yıldız ve Gizir, 2018). Bu geçiş, yükseköğretim kurumlarını kendilerini yeniden gözden geçirerek işlevlerinin verimliliğini ve etkililiğini arttırmaya yönelik çalışmalar yapmaya zorlamaktadır (Ekinci ve Burgaz, 2007). Bu çalışmaların başında ise hem ulusal hem de uluslararası "eğitim pazarı"ndaki öğrencileri kendine çekebilecek bir hizmet kalitesinin sağlanması gelmektedir (Popli, 2005; Trivellas ve Geraki, 2008). Bu amaçla kurulan kalite güvence sistemleriyle, yükseköğretim kurumları amaç, yapı, süreç ve çıktıları açısından ele alınıp değerlendirilmekte ve bu kurumların eğitim-öğretim ve araştırma faaliyetleri ile idarî hizmetlerinin kalite düzeyleri belirlenmektedir (Yükseköğretim Kalite Güvencesi Yönetmeliği, 2015). Yüksek hizmet kalitesine sahip olan kurumlar, rakiplerinden farklı bir konuma gelerek tüm paydaşlar açısından tercih edilen, saygın, güvenilir ve itibarlı bir üniversite olarak görülmektedir (Koçoğlu, 2018).

Üniversitelerin paydaşları iç ve dış paydaş olmak üzere ikiye ayrılmaktadır (Amaral ve Magalhaes, 2002; Musial, 2010). İç paydaşlarından bazıları öğrenciler, akademik personel ve idari personel iken dış paydaşlarından bazıları ise mezunlar, işverenler, işletmeler, meslek örgütleri ve toplumdur (Marshall, 2018). Üniversitelerin iç paydaşlarından biri ve eğitim pazarında müşteri konumunda olan öğrencilerin kendilerine sunulan eğitim-öğretim hizmetinin kalitesinden memnun olup olmadığı kalite çalışmalarını önemseyen üniversiteler için önem arz eden bir konudur (Marzo-Navarro, Pedraja-Iglesias ve Rivera-Torres, 2005; McCuddy, Pinar ve Gingerich, 2008; Popli, 2005). Çünkü memnuniyet, sunulan bir hizmetin tatmin edici bir biçimde yerine getirilip getirilmediğini ortaya koyan en iyi kanttlardan birisidir (Browne, Kaldenberg, Browne ve Brown, 1998; Guolla, 1999; Oliver, 1999). Öğrenci memnuniyeti, üniversitelerin sağladığı eğitim-öğretim hizmetlerinin çeşitli boyutlarına ilişkin öğrencilerin görüşlerinin elde edilmesiyle tespit edilebilmektedir (Dolmans, Wolfhagen ve Scherpbier, 2003).

Karmaşık ve çok yönlü olması nedeniyle, yükseköğretimde kalite kavramının genel geçer tek bir tanımı olmasa da öğrenci bakış açısı temel alındığında 'öğrencilerin almayı beklediği ile gerçekte aldığı hizmet arasındaki fark' olarak tanımlanabilmektedir (Harvey ve Green, 1993; O’Neill ve Palmer, 2004, s.42). Öğrencilerin akademik, kişisel ve sosyal gelişimlerine katk1 sağladığı düşünülen yükseköğretimde hizmet kalitesinin farklı birçok boyuta sahip olduğu alan yazında bahsedilmiştir (Ardi, Hidayatno ve Zagloel, 2012; Bayraktar, Tatoglu ve Zaim, 2008; Hasan, Ilias, Rahman ve Razak, 2008; Lagrosen, Seyyed-Hashemi ve Leitner, 2004; Sakthivel, Rajendran ve Raju, 2005; Sayeda, Rajendran ve Lokachari, 2010; Tsinidou, Gerogiannis ve Fitsilis, 2010). Bu çalışma kapsamında ise yükseköğretimde hizmet kalitesi bağlamında önemli görülen ve incelemek üzere ele alınan boyutlar şunlardır: öğretim elemanları ve dersler, danışmanlık hizmetleri, üniversite veya bölüm yöntemi, kurumun sahip olduğu fiziksel ve teknolojik alt yapı ve donanımlar.

$\mathrm{Bu}$ boyutlardan ilki, üniversitedeki öğretim elemanlarının özelliklerine ilişkin boyuttur. Öğretim elemanlarının alana ilişkin sahip olduğu bilgi düzeyi ve akademik yeterliliği, öğrenme- 
öğretme sürecini iyi planlayıp uygulayabilmesi ve öğrencilerle etkili iletişim ve etkileşim kurabilmesi sunulan hizmet kalitesinin en önemli ögelerinden biridir (Harnash-Glezer ve Meyer, 1991; Hill, Lomas ve MacGregor, 2003; Kuh ve Hu, 2001; Pozo-Munoz, Rebolloso-Pacheco ve Fernandez-Ramirez, 2000; Voss ve Gruber, 2006). Öğrencilerin özellikle akademik gelişimlerine en büyük katkıyı, öğretim elemanlarının performanslarının ve kullandıkları öğretim yöntemlerinin sağladığ 1 tespit edilmiştir (Edström, 2008; Wachtel, 1998). Bununla birlikte ödev, proje ve sınavları etkili kullanan, öğrencilerin mantıksal akıl yürütmesini sağlayan ve yetenek gelişimini destekleyen öğretim elemanlarından eğitim-öğretim almanın öğrencilerin memnuniyet düzeylerini artırdığı belirtilmiştir (Dalton ve Denson, 2009; Sproule, 2000).

Diğer bir boyut, öğrencilere sunulan danışmanlık hizmetleridir. Gerek kişisel gerekse akademik problemlerle karşılaşan öğrencilere destek ve yardım sunma amacıyla oluşturulan danışmanlıklar, öğrencilerin memnuniyetini etkileyen önemli bir faktördür (Palli ve Mamilla, 2012). Danışmanların öğrencilerle iletişime açık olması ve öğrencilerin rehberlik veya danışmanlığa ihtiyaç duydukları bir durumda danışmanlarına rahatlıkla ulaşabilmesi yaşanan sorunların başarılı bir şekilde ortadan kaldırılması için oldukça gereklidir (King, 1993).

Bununla birlikte, öğrencilerin eğitim hizmeti aldığ üniversitenin veya bölümün yönetimiyle olan ilişkisi memnuniyet düzeyini etkileyen faktörlerden birisidir. Öyle ki üniversitelerin kaliteli bir eğitim anlayışına sahip olmasının yanı sıra kaliteli bir yönetim düşüncesine de sahip olması öğrencilerin memnuniyetini etkilemektedir (Peker, 1994). Öğrencilerin üniversitenin veya bölümün yöneticilerini tanımas1, gerektiğinde onlara ulaşabilmesi ve bir paydaş olarak yönetimde söz hakkına sahip olabilmesi öğrencilerin aidiyet duygularını geliştirmektedir (Bean, 1983). Gerektiğinde akademik, kişisel ya da sosyal gelişime katk1 sağlayacak etkinliklerin düzenlenmesinde yönetimden destek alabilme öğrencilerin yaşayacakları deneyimlerini dolayısıyla eğitim-öğretim hizmetinden memnun kalma düzeylerini etkileyebileceği belirtilmiştir (Aypay, Aypay ve Demirhan, 2009).

Son olarak, üniversitelerin fiziksel ve teknolojik alt yapıları ve donanımları da öğrenci memnuniyetini etkileyen en önemli faktörlerden biridir (Aydın, Görmüş ve Altıntop, 2014). Eğitim verilen ortamların temizlik, güvenlik ve yeterlik düzeyleri, sunulan bilişim ve teknolojik donanım ve destek olanakları, kütüphane, fotokopi, bilgisayar, internet olanakları ve kampüs içerisinde ders dışında sosyalleşme ve ortak etkinlik yapılabilecek mekânların, yemekhane ve kafeterya gibi yerlerin sağlanması günümüz eğitim kurumlarının sahip olması gereken temel özellikler arasındadır (Arambewela ve Hall, 2007; Athiyaman, 1997; Ford, Joseph ve Joseph, 1999; Harvey, 2001; Joseph, Yakhou ve Stone, 2005).

Öğrenciler üniversitelerin sunmuş olduğu eğitim hizmetlerinin doğrudan alıcıs1 konumunda olduğundan yapacakları değerlendirmeler kalite artırma çalışmalarına yararlı dönütler sunan bilgi kaynaklarından birisidir (McCuddy ve diğerleri, 2008). Özellikle öğrenci memnuniyet düzeyinin tespiti, üniversitenin öğrencilerine sunmuş olduğu imkânların ve hizmetin kalite düzeyini ortaya koyan geçerli ve güvenilir bilgiler sağlamaktadır (Browne ve diğerleri, 1998; Guolla, 1999; Oliver, 1999; Penny, 2003). Bunun yanında, küresel rekabetin arttığı günümüzde, en çok tercih edilen başarılı üniversite sıralamalarında en üst sıralarda yer almayı hedefleyen üniversiteler öğrenci memnuniyetine ilişkin elde ettikleri bilgilere dayanarak kurumsal etkililiğini ve verimliliğini de ispat edebilmektedir (Arambewela ve Hall, 2007; Ford ve diğerleri, 1999; Kwek, Lau ve Tan, 2010). Bu durumun son yllarda kalite geliştirme 
çalışmalarına hız vermiş olan Türkiye'deki yükseköğretim kurumları için de geçerli olduğu düşünülmektedir. Nitelikli öğretmen yetiştirmeyi amaçlayan eğitim fakülteleri ise sunduğu hizmetin ve öğretmenlik programlarının kalitesini sürekli olarak iyileştirme yönünde adımlar atmaktadır (Adıgüzel ve Sağlam, 2009; Azar, 2011). Ancak alan yazındaki çalışmalar genel olarak incelendiğinde; öğretmen adaylarının kendilerine sunulan hizmet kalitesinden orta veya iyi düzeyde memnun olduğu görülmüştür (Açan ve Saydan, 2009; Dolmans ve diğerleri, 2003; Kaya ve Engin, 2007; Özcan, 2013; Şahin, 2009; Şara ve Kocabaş, 2012; Tatlı Haliloğlu, Kokoç ve Karal, 2011; Uzgören ve Uzgören, 2007). Bununla birlikte, öğretmen adaylarının eğitim fakültelerinden beklentilerinin yüksek ancak memnuniyetlerinin düşük olduğunu ortaya koyan çalışmalar vardır (Awang ve İsmail, 2010; Ekinci ve Burgaz, 2007).

\section{Araştırmanın Amacı ve Önemi}

Yükseköğretim kurumlarının sunduğu eğitim-öğretim hizmetlerinin öğrenciler tarafından değerlendirilmesine vurgu yapan bu çalışmada, Mersin Üniversitesi Eğitim fakültesindeki öğretmen adaylarının, fakültedeki hizmet kalitesine yönelik memnuniyet düzeylerinin betimsel olarak incelenmesi amaçlanmıştır. Öğretmen adaylarının eğitim fakültesindeki öğretim elemanlarından, danışmanlık hizmetlerinden, bölüm ve okul yönetiminden, ders programlarından ve fiziksel olanaklardan memnun olmalarının hem eğitim hayatlarına hem de akademik başarılarına katkı sağlayacağı düşünülmektedir. Öğrencilerin üniversitede sunulan hizmetlerden memnun olma düzeyi o üniversitenin kalitesine yönelik bir gösterge olarak kabul edilebilmektedir. $\mathrm{Bu}$ nedenle, öğrenci görüşlerine göre tespit edilen güçlü yanların sürdürülebilmesi ve zayıf yönlerin ise iyileştirilmesine yönelik üniversitelere fikir sunması açısından bu araştırma önemli görülmektedir. Ayrıca nitelikli öğretmen yetiştirmeyi amaçlayan eğitim fakültelerinin sunduğu hizmetin ve öğretmenlik programlarının kalitesine ilişkin durum tespiti yapması açısından ilgili alan yazına katkı sağlayacağı düşünülmektedir. Araştırmanın amacı doğrultusunda belirlenen aşağıdaki alt problemlere yanıtlar aranmıştır:

1. Öğretmen adaylarının eğitim fakültesindeki hizmet kalitesine yönelik memnuniyetleri ne düzeydedir?

2. Öğretmen adaylarının eğitim fakültesindeki a) öğretim elemanları, b) danışmanlık, c) bölüm ve okul yönetimi, d) ders ve ders programları, e) fiziksel olanaklardan memnun olma düzeyleri nedir?

3. Öğretmen adaylarının eğitim fakültesindeki hizmet kalitesine yönelik memnuniyetleri cinsiyete göre farklılık göstermekte midir?

4. Öğretmen adaylarının eğitim fakültesindeki hizmet kalitesine yönelik memnuniyetleri bölüme göre farkl1lık göstermekte midir?

\section{Yöntem}

Öğretmen adaylarının eğitim fakültesindeki hizmet kalitesine yönelik memnuniyet düzeylerini betimlemeyi amaçlayan bu araştırma betimsel araştırma yöntemlerinden tarama modelinde gerçekleştirilmiştir. 


\section{Çalışma Grubu}

Araştırmanın çalışma grubu, araştırmaya hız ve pratiklik kazandıran uygun örnekleme yöntemi kullanılarak belirlenmiştir. Araştırmanın evrenini, 2016-2017 öğretim y1lı güz ve bahar döneminde, Mersin Üniversitesi Eğitim Fakültesi'nin farklı bölümlerinde eğitim gören bütün öğretmen adayları oluşturmaktadır. Örneklem ise bu evrenden ulaşılan 674 öğretmen adayından oluşmaktadır. Öğretmen adaylarının cinsiyete ve bölümlere göre frekans ve yüzde değerleri Tablo 1'de verilmiştir.

Tablo 1. Öğretmen Adaylarının Cinsiyet ve Bölüm Bilgilerine İlişkin Frekans ve Yüzde Değerleri

\begin{tabular}{llcc}
\hline & & $\mathrm{f}$ & $\%$ \\
\hline Cinsiyet & Kadın & 466 & 69.10 \\
& Erkek & 208 & 30.90 \\
& Toplam & 674 & 100 \\
\hline Bölüm & İngilizce Öğgrt. & 156 & 23.10 \\
& Matematik Ögrt. & 112 & 16.60 \\
& PDR & 100 & 14.80 \\
& Türkçe Öğrt. & 84 & 12.50 \\
& Sinff Öğrt. & 78 & 11.60 \\
& Fen Bilgisi Öğrt. & 76 & 11.30 \\
& Okul Öncesi Öğgrt. & 42 & 6.20 \\
& Bilgisayar ve Ögretim Teknolojileri Eğitimi (BÖTE) & 26 & 3.90 \\
& Toplam & 674 & 100 \\
\hline
\end{tabular}

Tablo 1'de görüldüğü üzere, çalışma grubunu oluşturan öğretmen adaylarının 208'i erkek (\%30.90) ve 466'sı kadındır (\%69.10). Sekiz farklı bölüme kayıtlı olan öğretmen adaylarının \%23.10’u İngilizce Öğretmenliği, \%16.60’1 Matematik Öğretmenliği, \%14.80’i PDR, \%12.50'si Türkçe Öğretmenliği, \%11.60’1 Sinıf Öğretmenliği, \%11.30’u Fen Bilgisi Öğretmenliği, \%6.20’si Okul Öncesi Öğretmenliği ve \%3.90’1 ise BÖTE bölümünde eğitim almaktadır.

\section{Çalışmada Kullanılan Ölçme Araçları}

\section{Eğitim fakültesi öğrenci memnuniyet ölçeği}

Verilerin toplanmasında Şahin (2009) tarafindan geliştirilen 'Eğitim Fakültesi Öğrenci Memnuniyet Ölçeği' kullanılmıştır. Bu araştırma kapsamında elde edilen verilerden hesaplanan iç tutarlılık katsayıları ölçeğin bütünü için 0.96 iken; "Öğretim Elemanları" alt boyutu için 0.91, "Danışmanlık" alt boyutu için 0.86, "Yönetim" alt boyutu için 0.83 , "Kaynaklar" alt boyutu için 0.87, "Bilgisayar Olanakları" alt boyutu için 0.79, "Dersler ve Ders Programları" alt boyutu için 0.86 'dır. Ölçeğin altı faktörlü yapısının geçerliğini değerlendirmek için doğrulayıcı faktör analizi (DFA) yapılmıştır. Yapılan DFA sonucunda elde edilen tüm uyum indekslerinin kabul sınırları arasında yer aldığ $=2.82, \mathrm{CFI}=0.96, \mathrm{NNFI}=0.95, \mathrm{RMSEA}=0.06, \mathrm{SRMR}=0.06)(\mathrm{Hu}$ ve Bentler, 1999; Kline, 2005; McDonald ve Ho, 2002; Şimşek, 2007).

\section{İşlem}

Kullanılan ölçeğin bu çalışmanın örneklemine göre değişebilecek psikometrik niteliklerini belirlemek amaciyla, öncelikle uygulamadan elde edilen veri setinin $(\mathrm{N}=700)$ yapılacak parametrik testlere olan uygunluğu incelenmiştir. Yapılan incelemelerden sonra eksik veya yanlış doldurulmuş 16 adet cevaplayıcı ve 10 adet uç değer veri setinden çıkarılmıştır. Ardından 
elde edilen veri setinin $(\mathrm{N}=674)$ normalliğini incelemek üzere merkezi eğilim ölçüleri, ortalamadan sapma ölçüleri, çarpıklık ve basıklık katsayıları hesaplanmış ve Tablo 2'de verilmiştir.

Tablo 2. Verilere Ait Betimsel İstatistikler

\begin{tabular}{lccccccccc}
\hline & Min. & Maks. & $\overline{\mathrm{X}}$ & SH & Ss & Çarpıklık & SH & Basıklık & SH \\
\hline Dersler ve Ders Programları & 1.00 & 5.00 & 3.07 & 0.03 & 0.88 & -0.13 & 0.09 & -0.23 & 0.19 \\
Öğretim Elemanları & 1.00 & 5.00 & 3.03 & 0.03 & 0.82 & -0.04 & 0.09 & -0.34 & 0.19 \\
Danışmanlık & 1.00 & 5.00 & 2.68 & 0.04 & 0.97 & -0.06 & 0.09 & -0.35 & 0.19 \\
Bilgisayar Olanakları & 1.00 & 5.00 & 2.61 & 0.04 & 0.93 & 0.14 & 0.09 & -0.31 & 0.19 \\
Yönetim & 1.00 & 5.00 & 2.52 & 0.03 & 0.82 & 0.10 & 0.09 & -0.13 & 0.19 \\
Kaynaklar & 1.00 & 4.70 & 2.47 & 0.03 & 0.81 & 0.16 & 0.09 & -0.31 & 0.19 \\
Toplam Puan & 1.00 & 4.60 & 2.73 & 0.03 & 0.72 & 0.11 & 0.09 & -0.30 & 0.19 \\
\hline $\mathrm{n}=674$ & & & & & & & & &
\end{tabular}

Büyük örneklemlerden $(n>200)$ elde edilen verilerin normallik değerlendirmelerinde, dağılımın normalden aşırı sapmadığı halde normal olmadığı sonucuna götüren KolmogorovSmirnov gibi normallik testleri yerine örneklemden görece bağımsız olduğu için veri setindeki puanların çarpıklık ve basıklık değerlerinin standart hatalarıyla birlikte incelenmesi önerilir (Mertler ve Vannatta, 2005). Tablo 2'de görüldüğü üzere, ölçeğin bütününden ve alt boyutlarından alınan puanlarının çarpıklık ve basıklık değerlerinin standart hatalarına bölündüğünde elde edilen değerlerin -1.96 ile +1.96 arasında olması nedeniyle dağılımın normal olduğu ve elde edilen veri setinin yapılacak olan parametrik testlerin kullanımına uygun olduğu varsayılmıştır (Tabachnick ve Fidell, 2013).

\section{Verilerin Analizi}

Uygulanan ölçek sonucunda elde edilen verilerin geçerli ve güvenilir olması ve normallik varsayımlarını karşılaması parametrik test ön koşullarını sağlamaktadır. Veriler üzerinde yapılan istatistiksel çözümlemeler SPSS 20 ve LISREL 8.7 istatistik paket programları kullanılarak yapılmıştır. Buna göre verilerin analizinde;

- Araştırmaya katılan öğretmen adaylarının demografik özelliklerine ilişkin istatistiklerde frekans (f) ve yüzde (\%);

- Öğretmen adaylarının hizmet kalitesine yönelik memnuniyet düzeylerine ilişkin betimsel istatistikler;

- Öğretmen adaylarının hizmet kalitesine yönelik memnuniyetlerinin cinsiyete göre istatistiksel olarak anlamlı farklılık gösterip göstermediğini belirlemek amacıyla Bağımsız Grup t Testi,

- Öğretmen adaylarının hizmet kalitesine yönelik memnuniyetlerinin bölümlere göre istatistiksel olarak anlamlı farklılık gösterip göstermediğini belirlemek amacıyla Tek Yönlü ANOVA kullanılmıştır. İstatistiksel olarak anlamlı farklılıkların hangi bölümler arasında olduğunu belirlemek amaciyla grup varyanslarının homojen ancak örneklem büyüklükleri arasındaki farkın büyük olduğu durumlarda alpha tipi hataya karşı duyarlı olan Scheffe çoklu karşılaştırma tekniği; grup varyanslarının homojen olmadığı ve 
örneklem büyüklüklerinin oldukça farkl1laştı̆̆ durumlarda ise Games-Howell çoklu karşılaştırma tekniği tercih edilmiştir (Field, 2009).

- Grup dağılımlarının varyanslarının homojen olup olmadığg hipotezi Levene's testi ile sınanmıştır.

- Ölçekten alınan puanların değerlendirilmesinde kullanılan puan aralığı ise şöyledir: 12.33 arası düşük, 2.34-3.67 arası orta ve 3.68-5 arası yüksek.

\section{Bulgular}

Öğretmen adaylarının eğitim fakültesindeki hizmet kalitesine yönelik memnuniyet düzeylerine ilişkin betimsel istatistik sonuçları Tablo 3'te verilmiştir.

Tablo 3. Öğretmen Adaylarının Hizmet Kalitesine Yönelik Memnuniyet Düzeylerine İlişkin Betimsel İstatistikler

\begin{tabular}{lccccc}
\hline & Min. & Maks. & $\overline{\mathrm{X}}$ & SH & Ss \\
\hline Dersler ve Ders Programları & 1.00 & 5.00 & 3.07 & 0.03 & 0.88 \\
Öğretim Elemanları & 1.00 & 5.00 & 3.03 & 0.03 & 0.82 \\
Danışmanlık & 1.00 & 5.00 & 2.68 & 0.04 & 0.97 \\
Bilgisayar Olanakları & 1.00 & 5.00 & 2.61 & 0.04 & 0.93 \\
Yönetim & 1.00 & 5.00 & 2.52 & 0.03 & 0.82 \\
Kaynaklar & 1.00 & 4.70 & 2.47 & 0.03 & 0.81 \\
Toplam Puan & 1.00 & 4.60 & 2.73 & 0.03 & 0.72 \\
\hline
\end{tabular}

Tablo 3 'te görüldüğü üzere, öğretmen adaylarının eğitim fakültesinde sunulan hizmet kalitesine yönelik memnuniyetlerinin orta düzeyde olduğu gözlenmiştir (Ort.=2.73; Ss=0.72). Ölçekten alınan toplam puan ortalaması, eğitim fakültesinin sahip olduğu olanaklar çerçevesinde öğretmen adaylarına sunmaya çalıştığı hizmetin öğretmen adaylarınca orta düzeyde kaliteli olarak algılandığını göstermektedir. Ölçeğin alt boyutlarından alınan puan ortalamaları incelendiğinde ise öğretmen adaylarının sırasıyla derslerden ve ders programlarından, öğretim elemanlarından, danışmanlıktan, bilgisayar olanaklarından, yönetimden ve kaynaklardan orta düzeyde memnun oldukları tespit edilmiştir.

Öğretmen adaylarının eğitim fakültesindeki hizmet kalitesine yönelik memnuniyet düzeylerinin cinsiyet değişkenine göre farklılaşıp farklılaşmadığını belirlemek amacıyla yapılan Bağımsız Grup t testi sonuçları Tablo 4'te verilmiştir.

Tablo 4'te görüldüğü üzere, yapılan analiz sonucunda öğretim elemanları, danışmanlık hizmetleri, kaynaklar ve bilgisayar olanakları alt boyutlarında ve toplam puan ortalamasında tespit edilen istatistiksel olarak anlamlı farklar erkek öğretmen adaylarının, kadın öğretmen adaylarından daha memnun olduğunu göstermektedir. Yönetim ile dersler ve ders programlarından memnuniyet düzeylerinde ise istatistiksel olarak anlamlı bir fark bulunmamıştır ( $\mathrm{p}>.05)$. 
Tablo 4. Öğretmen Adaylarının Memnuniyet Düzeylerinin Cinsiyete Göre İncelenmesine İlişkin Bağımsız Grup t Testi Sonuçları

\begin{tabular}{|c|c|c|c|c|c|c|c|c|}
\hline \multirow[b]{2}{*}{ Puanlar } & \multirow[b]{2}{*}{ Gruplar } & \multicolumn{4}{|c|}{ Betimsel istatistikler } & \multicolumn{3}{|c|}{$\mathrm{t}$ testi } \\
\hline & & $\mathrm{n}$ & $\overline{\mathrm{X}}$ & Ss & $\mathrm{SH}$ & $\mathrm{t}$ & sd & $\mathrm{p}$ \\
\hline \multirow{2}{*}{ Öğretim Elemanları } & Kadın & 466 & 2.97 & 0.81 & 0.04 & \multirow{2}{*}{-2.67} & \multirow{2}{*}{672} & \multirow{2}{*}{$.01 *$} \\
\hline & Erkek & 208 & 3.15 & 0.84 & 0.06 & & & \\
\hline \multirow{2}{*}{ Yönetim } & Kadın & 466 & 2.51 & 0.71 & 0.03 & \multirow{2}{*}{-.64} & \multirow{2}{*}{672} & \multirow{2}{*}{.52} \\
\hline & Erkek & 208 & 2.55 & 1.01 & 0.07 & & & \\
\hline \multirow{2}{*}{ Danışmanlık } & Kadın & 466 & 2.63 & 0.97 & 0.04 & \multirow{2}{*}{-2.35} & \multirow{2}{*}{672} & \multirow{2}{*}{$.02 *$} \\
\hline & Erkek & 208 & 2.82 & 0.96 & 0.07 & & & \\
\hline \multirow{2}{*}{ Kaynaklar } & Kadın & 466 & 2.40 & 0.78 & 0.04 & \multirow{2}{*}{-3.34} & \multirow{2}{*}{672} & \multirow{2}{*}{$.00^{*}$} \\
\hline & Erkek & 208 & 2.62 & 0.86 & 0.06 & & & \\
\hline \multirow{2}{*}{ Bilgisayar Olanakları } & Kadın & 466 & 2.53 & 0.91 & 0.04 & \multirow{2}{*}{-3.41} & \multirow{2}{*}{672} & \multirow{2}{*}{$.00 *$} \\
\hline & Erkek & 208 & 2.79 & 0.95 & 0.07 & & & \\
\hline \multirow{2}{*}{ Dersler ve Ders Programları } & Kadın & 466 & 3.07 & 0.85 & 0.04 & \multirow{2}{*}{-.21} & \multirow{2}{*}{672} & \multirow{2}{*}{.84} \\
\hline & Erkek & 208 & 3.08 & 0.94 & 0.06 & & & \\
\hline \multirow{2}{*}{ Toplam Puan } & Kadın & 466 & 2.68 & 0.69 & 0.03 & \multirow{2}{*}{-2.68} & \multirow{2}{*}{672} & \multirow{2}{*}{$.01 *$} \\
\hline & Erkek & 208 & 2.84 & 0.77 & 0.05 & & & \\
\hline
\end{tabular}

Öğretmen adaylarının eğitim fakültesindeki hizmet kalitesine yönelik memnuniyet düzeylerinin bölüme göre farklılaşıp farklılaşmadığını belirlemek amacıyla yapılan Tek Yönlü Varyans Analizi sonuçları Tablo 5'te verilmiştir.

Tablo 5 toplam puan ortalamaları bazında incelendiğinde, öğretmen adaylarının eğitim fakültesindeki hizmet kalitesinden memnun olma düzeylerinde bölümlere göre anlamlı farkl11ıkların olduğu görülmektedir $\left(\mathrm{F}_{7-666}=8.97, \mathrm{p}<.05\right)$. İlk farkl1lık, BÖTE'deki öğretmen adaylarının memnuniyet düzeyinin (Ort=3.32, Ss=0.51), Türkçe Öğretmenliği (Ort=2.98, $\mathrm{Ss}=0.79$ ) hariç diğer altı bölümdeki öğretmen adaylarınkinden daha yüksek olmasıdır. Diğer farklı1ık, Okul Öncesi Öğretmenliği (Ort=2.38, Ss=0.57) ile BÖTE, Fen Bilgisi Öğretmenliği (Ort=2.81, Ss=0.62), İngilizce Öğretmenliği (Ort=2.81, Ss=0.76) ve Türkçe Öğretmenliği'ndeki öğretmen adayları arasında olup Okul Öncesi Öğretmenliği’ndeki öğretmen adayları aleyhinedir. Diğer bir farklılık, Sınıf Öğretmenliği (Ort=2.42, Ss=0.75) ile BÖTE, Fen Bilgisi Öğretmenliği, İngilizce Öğretmenliği ve Türkçe Öğretmenliği'ndeki öğretmen adayları arasında olup Sınıf Öğretmenliği’ndeki öğretmen adayları aleyhinedir. Son farklılık ise Türkçe Öğretmenliği ile PDR (Ort=2.61, Ss=0.60) arasında olup Türkçe Öğretmenliği’ndeki öğretmen adayları lehinedir.

Tablo 5 hizmet kalitesinin alt boyutlarına ait puan ortalamaları bazında incelendiğinde ise öğretmen adaylarının memnuniyet düzeylerindeki bölümlere göre farklılaşmaların en çok öğretim elemanları, kaynaklar, dersler ve ders programları ve yönetim alt boyutlarında; en az ise bilgisayar olanakları ve danışmanlık alt boyutlarında olduğu görülmektedir. Alt boyutlara ait puan ortalamalarında tespit edilen istatistiksel olarak anlamlı farklar ise genel olarak BÖTE ve Türkçe Öğretmenliği'ndeki öğretmen adaylarının memnuniyet düzeyinin diğer altı bölümdeki öğretmen adaylarınkinden daha yüksek olduğunu; Okul Öncesi ve Sınıf Öğretmenliği’ndeki öğretmen adaylarının memnuniyet düzeyinin ise diğer bölümlerdeki öğretmen adaylarınkinden daha düşük olduğunu göstermektedir. 
Tablo 5. Öğretmen Adaylarının Memnuniyet Düzeylerinin Bölümlere Göre İ́ncelenmesine İlişkin Tek Yönlü Varyans Analizi (ANOVA) Sonuçları

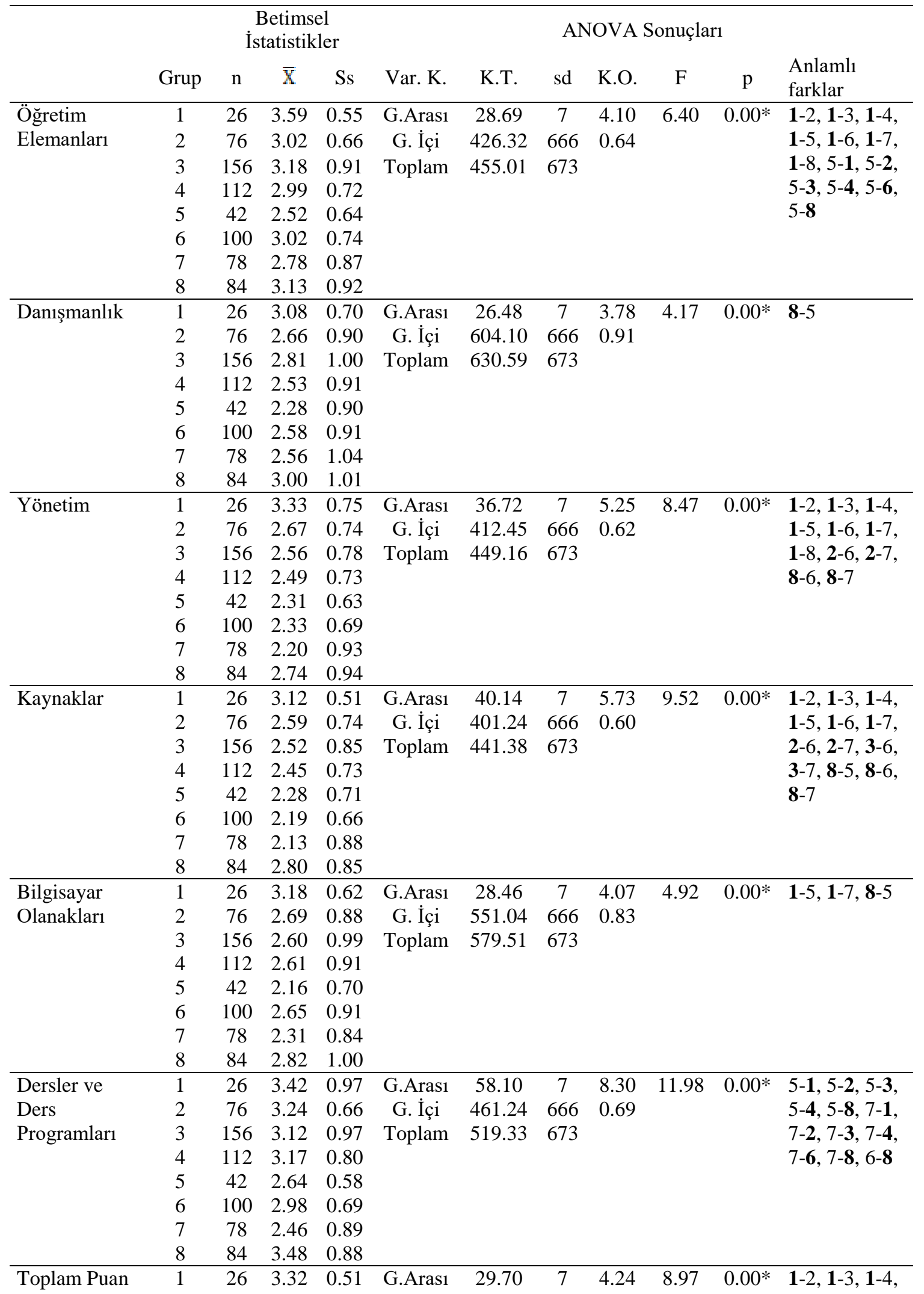




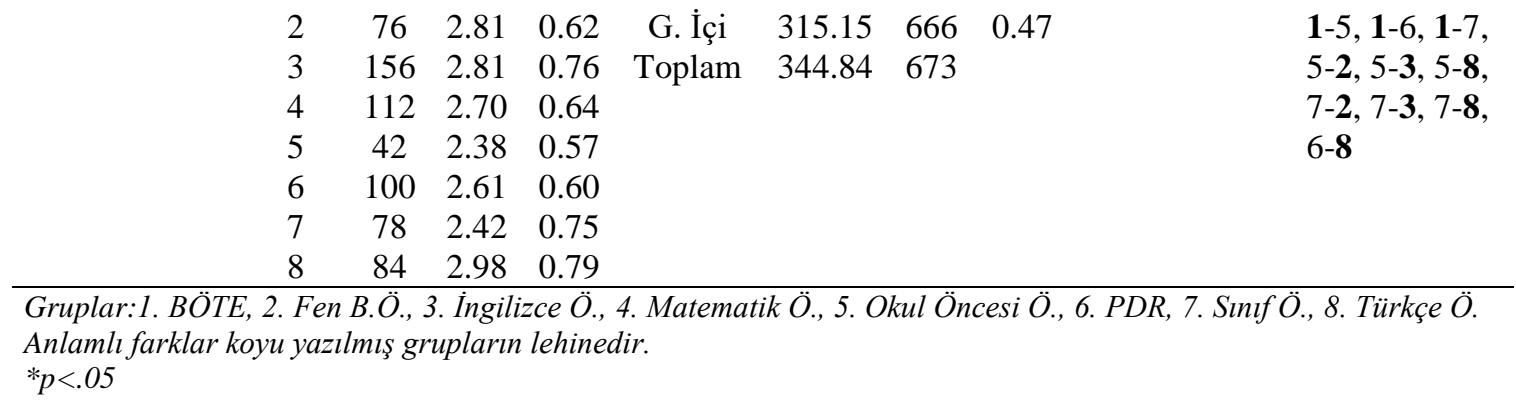

\section{Tartışma ve Sonuç}

Yükseköğretim kurumlarının sunduğu eğitim-öğretim hizmetlerinin öğrenciler tarafından değerlendirilmesine vurgu yapan bu çalışmada, öğretmen adaylarının eğitim fakültesindeki hizmet kalitesine yönelik memnuniyet düzeylerinin belirlenmesi ve betimsel olarak incelenmesi amaçlanmıştır. Elde edilen veriler üzerinde yapılan analiz sonuçları, genel olarak öğretmen adaylarının eğitim fakültesinde sunulan hizmet kalitesine yönelik memnuniyetinin orta düzeyde olduğunu göstermiştir. Bu bulgu, eğitim fakültesinin sahip olduğu olanaklar çerçevesinde öğretmen adaylarına sunmaya çalıştı̆̆ hizmetin genel anlamda öğretmen adaylarınca orta düzeyde kaliteli olarak algılandığını göstermektedir. Sunulan hizmet kalitesinin alt boyutları ele alındığında ise öğretmen adaylarının fakülte ve bölümlerinde sunulan zorunlu ve seçmeli derslerin içerik ve kapsamlarından ve yapılan ders programlarından; fakültenin öğretim elemanlarının öğretme becerilerinden, ders dışında yönlendirme, destek ve yardım düzeylerine kadar birçok özelliğinden; kendilerine sunulan danışmanlık hizmetlerinden ve yönetimden orta düzeyde memnun olduğu ve fakültedeki fiziksel ve teknolojik alt yapıyı ve kütüphanesindeki kaynakları yeterli bulmadığı sonucu çıkarılabilir. Bu bulgular, Ekinci ve Burgaz'ın (2007) Hacettepe Üniversitesi genelinde yürüttükleri araştırmanın sonuçlarıyla paralellik taşımaktadır. Araştırma sonucunda, öğrencilerin beklentilerinin yüksek, memnuniyet düzeylerinin ise düşük olduğu ortaya çıkmıştır. Benzer şekilde, öğretmen adaylarının memnuniyet düzeylerini ardışık üç yıl boyunca inceleyen Şahin (2009), öğretmen adaylarının memnuniyet düzeylerinin genel olarak artış göstermesine rağmen özellikle yönetim, kaynaklar ve bilgisayar olanakları alt boyutlarında oldukça düşük iken öğretim elemanları, danışmanlık ve dersler ve ders programları alt boyutlarında orta düzeyde olduğunu tespit etmiştir. Çalışmasında üniversite öğrencilerinin öğretim kalitesini değerlendirmelerini isteyen Özcan (2013) ise hem yeni kurulan hem de gelişmekte olan üniversitelerin (Adiyaman, Çoruh, Cumhuriyet, Marmara ve Sakarya Üniversiteleri) eğitim fakülteleri arasında öğretim kalitesi yönünden bir farklılığın olmadığ1 ancak öğretmen adaylarının algılarına göre eğitim fakültelerinde kalite sorunu olduğu sonucuna varmıştır. Alan yazın ile de desteklenen bu sonuçlar, kaliteli hizmet sunma sorununun sadece Mersin Üniversitesi Eğitim Fakültesi ile sınırlı olmadığını ülkemizdeki birçok eğitim fakültesini ilgilendiren bir konu olduğunu ortaya koymaktadır. Bu nedenle, özellikle bilim ve teknolojinin geliştiği, bilginin hızla yayıldığı ve hayatın neredeyse her alanında küresel rekabetin arttığı günümüzde eğitim fakültelerinin nitelikli öğretmen yetiştirme ve ülkemizin eğitim kalitesini yükseltme yolunda kurum olarak kendilerini yeniden gözden geçirerek işlevlerinin verimliliğini ve etkililiğini arttırmaya yönelik çalışmalar yapması gerektiği çıkarımında bulunulabilir (Ekinci ve Burgaz, 2007; Kaur ve Bhalla, 2018). Eğitim fakültelerinin hem iç paydaşlarından biri hem de hizmet alıcısı olan öğretmen adaylarının fakülte ve bölümler tarafından sunulan her türlü 
hizmete yönelik memnuniyeti, kurumların hizmet kalitesini ortaya koyan en iyi kanıtlardan biri olması nedeniyle büyük önem arz etmektedir (Browne ve diğerleri, 1998; Guolla, 1999; MarzoNavarro ve diğerleri, 2005; McCuddy ve diğerleri, 2008; Oliver, 1999; Popli, 2005). Ancak unutulmamalıdır ki bu çalışmada da olduğu gibi, alan yazındaki birçok araştırma üniversite ve fakültelerin diğer iç ve dış paydaşlarını dahil etmeden sadece öğretmen adaylarının görüş, beklenti, memnuniyet ve kalite algılarını temel almaktadır (Dolmans ve diğerleri, 2003; Ekinci ve Burgaz, 2007; Şahin, 2009; Özcan, 2013). Bu nedenle, sadece öğretmen adaylarından alınan verilere dayanarak varılacak sonuçların kurumların hizmet kalitesinin değerlendirilmesinde tek taraflı veya sınırlı kalabileceği de göz önünde bulundurulmalıdır.

$\mathrm{Bu}$ araştırma kapsamında çıkarılan sonuçlardan bir diğeri de kadın ve erkek öğretmen adaylarının memnuniyet düzeylerinin istatistiksel olarak farklılaşmasıdır. Cinsiyete göre öğretim elemanları, danışmanlık hizmetleri, kaynaklar, bilgisayar olanakları ve genel memnuniyet düzeyinde bulunan istatistiksel anlamlı farklar erkek öğretmen adaylarının, kadın öğretmen adaylarından daha memnun olduğunu ortaya koymuştur. Yönetim ile dersler ve ders programlarından memnun olma düzeylerinde ise cinsiyete göre istatistiksel olarak anlamlı bir fark bulunmamıştır. Alan yazında, üniversite öğrencilerinin memnuniyetini inceleyen çalışmalarda katılımcıların cinsiyetleri ile memnuniyet düzeylerine ilişkin çeşitli sonuçlar elde edilmiştir. Bazı çalışmalar öğretmen adaylarının memnuniyet düzeylerinin cinsiyete göre istatistiksel olarak anlamlı bir farklılık göstermediğini ortaya koymuştur (Özdemir, Kılınç, Öğdem ve Er, 2013; Tatlı Haliloğlu ve diğerleri, 2011). Bu çalışmanın sonucuna paralel olarak, bazı çalışmalar ise öğretmen adaylarının memnuniyet düzeylerinin cinsiyete göre farklılaştığını ortaya koymuştur (Çokluk-Bökeoğlu ve Yılmaz, 2007; Ilias, Hasan, Rahman ve Yasoa, 2008; Özdemir, 2012; Rienzi, Allen, Sarmiento ve McMillin, 1993; Umbach ve Porter, 2002; WiersJenssen, Stensaker ve Grøgaard, 2002). Konuya ilişkin alan yazında benzer ve farklı sonuçların ortaya çıkmasında çeşitli etkenlerin etkili olabileceği düşünülmektedir. Bunlardan birisi, araştırma grubundaki katılımcıların cinsiyet dağılımlarının birbirinden çok farklılaşması ve yapılan analizlerin farklı sonuçlar vermesi olabilir. Örneğin bu araştırmaya katılan öğretmen adaylarının yaklaşık yüzde yetmişi kadındır. Dolayısıyla bu çalışmadan elde edilen veriler ile kadın ve erkek öğretmen adaylarının eşit sayıda olduğu bir başka çalışmadan elde edilecek verilerin farklılaşması oldukça muhtemeldir. Buna ek olarak, öğretmen adaylarının memnuniyet düzeylerinin cinsiyete göre farklılaşması kadın ve erkek öğretmen adaylarının farklı beklenti, tutum veya algılara sahip olmasından da kaynaklanıyor olabilir (Çokluk-Bökeoğlu ve Yılmaz, 2007).

Son olarak, sekiz farklı bölüme kayıtlı olan öğretmen adaylarının eğitim fakültesindeki hizmet kalitesinden memnun olma düzeylerinin bölümlerine göre farklılaştı̆̆ varılmıştır. Elde edilen bulgular ışı̆̆ında, eğitim fakültesindeki hizmet kalitesinden en memnun öğretmen adaylarının BÖTE ve Türkçe Öğretmenliği bölümlerinden olduğu; en az memnun öğretmen adaylarının ise Okul Öncesi ve Sınıf Öğretmenliği bölümlerinden olduğu sonucuna varılmıştır. Alan yazın incelendiğinde, öğretmen adaylarının memnuniyet düzeylerinin bölümlere göre farklılık gösterip göstermediğini inceleyen çalışmaların birbirinden farklı sonuçlar ortaya koyduğu görülmektedir (Çokluk-Bökeoğlu ve Yılmaz, 2007; Özdemir, 2012; Özdemir ve diğerleri, 2013; Rienzi ve diğerleri, 1993; Tatlı Haliloğlu ve diğerleri, 2011; Umbach ve Porter, 2002). Bununla birlikte bu çalışmanın BÖTE'ye ilişkin sonuçlarına paralel olarak, Tatı Haliloğlu ve diğerleri (2011) yaptıkları çalışma sonucunda BÖTE'deki öğretmen 
adaylarının üniversitenin sunduğu olanaklardan orta derecede memnun olduğunu belirtmiş̧ir. Ayrıca bölüm öğretim elemanlarının ve idari personelinin kendilerine yönelik yaklaşımlarından oldukça memnun olan öğretmen adaylarının kütüphane, bilgisayar ve internet olanakları ile rehberlik ve danışmanlık hizmetlerini yeterli bulmadığı sonucuna varılmıştır.

Öğretmen adaylarının eğitim almakta oldukları eğitim fakültelerindeki öğretim elemanlarından, danışmanlık hizmetlerinden, bölüm ve okul yönetiminden, ders ve ders programlarından ve fiziksel olanaklardan memnun olmaları eğitim hayatlarına ve akademik başarılarına şüphesiz katkı sağlayacaktır. Öğretmen adaylarının, fakültelerinde sunulan hizmet kalitesinden memnun olma düzeyi o fakültenin yaşam kalitesine yönelik bir gösterge olarak da kabul edilirse, belirlenen eksikliklerin giderilmesi ve zayıf yönlerin güçlendirilmesi hem öğretmen adaylarının aldıkları eğitim-öğretim hizmetlerden memnun olmalarını hem de önce eğitim fakültesinin ardından da üniversitenin sahip olduğu kalitesini artırmasını sağlayacaktır.

\section{Öneriler}

Araştırmanın sonuçlarına dayanılarak eğitim fakülteleri için uygulamaya yönelik bazı öneriler sunulabilir. Örneğin, eğitim fakülteleri öğretmen adayları da dahil olmak üzere tüm iç ve dış paydaşlarını değerlendirme sürecine dahil ederek, sunduğu hizmet kalitesinin çok yönlü ve gerçekçi bir şekilde tespit ve değerlendirmesinin yapılmasını sağlayabilir. Ayrıca bu kalite tespit ve değerlendirme çalışmalarının düzenli olarak dönemde veya yılda en az bir kez yapılacak şekilde planlanması ve uygulanması önerilebilir. Böylece fakülteye ilişkin her türlü durum ve bilgilerin güncelliği sağlanarak geliştirilmesi gereken zayıf veya eksik alanlar belirlenebilir ve ihtiyaç duyulan alanlarda kalite artırma çalışmalarına yön verilebilir.

Gelecekte yapılacak araştırmalara yönelik bazı öneriler de sunulabilir. Örneğin, araştırmanın sonuçlarının eğitim fakültesi bazında genellenebilirliği açısından benzer bir araştırma, fakültedeki bütün bölümleri ve sınıfları temsil edebilen ve yaklaşık benzer sayıda kadın ve erkek öğretmen adaylarından oluşan daha büyük bir örneklemle yapılabilir. Eğitim fakültesinin hizmet kalitesine ilişkin daha çeşitli ve detaylı bilgi edinebilmek amacıyla, fakültenin tüm iç ve dış paydaşlarını değerlendirme sürecine dahil eden ve çeşitli nitel ve nicel veri toplama araçlarının kullanıldığ 1 boylamsal araştırmalar yapılabilir. Öğretmen adaylarının hizmet kalitesinden memnun olma durumlarını etkileyen başka faktörlerin olup olmadığının belirlenmesine yönelik daha derinlemesine araştırmalar ve görüşmeler yapılabilir. Son olarak eğitim fakültesinin hizmet kalitesini değerlendiren öğretmen adaylarının devamsızlık durumlarının da göz önünde bulundurulması, yapılacak çalışmaların ve varılacak sonuçların güvenirliğini ve geçerliğini artırabilir. 


\section{Kaynakça}

Açan, B. ve Saydan, R. (2009). Öğretim elemanlarının akademik kalite özelliklerinin değerlendirilmesi: Kafkas Üniversitesi İ̈BF örneği. Atatürk Üniversitesi Sosyal Bilimler Enstitüsü Dergisi, 13(2), 226-227.

Adıgüzel, A. ve Sağlam, M. (2009). Öğretmen eğitiminde program standartları ve akreditasyon. İпӧnü Üniversitesi Ĕ̈itim Fakültesi Dergisi, 10(3), 83-103.

Amaral, A. ve Magalhaes, A. (2002). The emergent role of external stakeholders in European higher education governance. In: Amaral, A., Jones, G. and Karseth, B. (Eds). Governing Higher Education: National Perspectives on Institutional Governance (pp. 1-21). Dordrecht: Kluwer Academic Publishers.

Arambewela, R. ve Hall, J. (2007). A model of student satisfaction: international postgraduate students from Asia. In Borghini, S., McGrath, M.A. and Otnes, C. (Eds). E-European Advances in Consumer Research Volume 8 (pp. 129-135). Duluth MN: Association for Consumer Research.

Ardi, R., Hidayatno, A. ve Zagloel, T.Y.M. (2012). Investigating relationships among quality dimensions in higher education. Quality Assurance in Education, 20(4), 408-428.

Athiyaman, A. (1997). Linking student satisfaction and service quality perceptions: the case of university education. European Journal of Marketing, 31(7), 528-540.

Awang, H. ve İsmail, N.A. (2010). Undergraduate education: a gap analysis of students' expectations and satisfaction. Problems of Education in the 21st Century, 21, 21-28.

Aydın, S., Görmüş, A.Ş. ve Altıntop, M.Y. (2014). Öğrencilerin memnuniyet düzeyleri ile demografik özellikleri arasındaki ilişkinin doğrusal olmayan kanonik korelasyon analizi ile incelenmesi: meslek yüksekokulu'nda bir uygulama. AİBÜ Sosyal Bilimler Enstitüsü Dergisi, 14(1), 35-58.

Aypay, A., Aypay, A. ve Demirhan, G. (2009). Öğrencilerin üniversiteye sosyal uyumu bir üniversite örneği. Uşak Üniversitesi Sosyal Bilimler Dergisi, 2(1), 46-64.

Azar, A. (2011). Türkiye'deki öğretmen eğitimi üzerine bir söylem: nitelik mi, nicelik mi? Yükseköğretim ve Bilim Dergisi, 1(1), 36-38.

Bayraktar, E., Tatoglu, E. ve Zaim, S. (2008). An instrument for measuring the critical factors of TQM in Turkish higher education. Total Quality Management \& Business Excellence, 19(6), 551-74.

Bean, J.P. (1983). The application of a model of turnover in work organizations to the student attrition process. The Review of Higher Education, 6(2), 129-148.

Browne, B., Kaldenberg, D., Browne, W. ve Brown, D. (1998). Student as customers: factors affecting satisfaction and assessments of institutional quality. Journal of Marketing for Higher Education, $8(3), 1-14$.

Çokluk-Bökeoğlu, Ö. ve Yılmaz, K. (2007). Üniversite öğrencilerinin fakülte yaşamının niteliğine ilişkin görüşlerinin çeşitli değişkenler açısından incelenmesi. Ankara Üniversitesi Eğitim Bilimleri Fakültesi Dergisi, 40(2), 179-204.

Dalton, H. ve Denson, N. (2009). Student evaluation: what predicts satisfaction? Proceedings of the 32nd HERDSA Annual Conference, Daarwin, 100-110.

Dolmans, D. H., Wolfhagen, H. A. ve Scherpbier, A. J. (2003). From quality assurance to total quality management: how can quality assurance result in continuous improvement in health professions education? Education for Health, 16(2), 210-217.

Edström, K. (2008) Doing course evaluation as if learning matters most. Higher Education Research \& Development, 27(2), 95-106.

Ekinci, C. E. ve Burgaz, B. (2007). Hacettepe üniversitesi öğrencilerinin bazı akademik hizmetlere ilişkin beklenti ve memnuniyet düzeyleri. Hacettepe Üniversitesi Eğitim Fakültesi Dergisi, 33, 120-134.

Field, A. (2009). Discovering Statistics Using SPSS (3rd Edition). London: Sage Publications Ltd. 
Ford, J.B., Joseph, M. ve Joseph, B. (1999). Importance-performance analysis as a strategic tool for service marketers: the case of service quality perceptions of business students in New Zealand and the USA. The Journal of Services Marketing, 13(2), 171-186.

Guolla, M. (1999). Assessing the teaching quality to student satisfaction relationship: applied customer satisfaction research in the classroom. Journal of Marketing Theory and Practice, 7(3), 87-97.

Harnash-Glezer, M. ve Meyer, J. (1991). Dimensions of satisfaction with collegiate education. Assessment \& Evaluation in Higher Education, 16(2), 95-107.

Harvey, L. (2001). Student feedback: A report to the higher education funding council for England. Research report, Centre for Research into Quality, The University of Central England, Birmingham, United Kingdom.

Harvey, L. ve Green, D. (1993). Defining quality. Assessment ve Evaluation in Higher Education, 18(1), 9-34.

Hasan, H.F.A., Ilias, A., Rahman, R. A. ve Razak, M. Z. A. (2008). Service quality and student satisfaction: a case study at private higher education institutions. International Business Research, 1(3), 163-175.

Hill, Y., Lomas, L. ve MacGregor, J. (2003). Students' perceptions of quality in higher education. Quality Assurance in Education, 11(1), 15-20.

$\mathrm{Hu}$, L.T. ve Bentler, P.M. (1999). Cutoff criteria for fit indexes in covariance structure analysis: conventional criteria versus new alternatives. Structural Equation Modeling: $A$ Multidisciplinary Journal, 6(1), 1-55.

Ilias, A., Hasan, H. F. A., Rahman, R. A. ve Yasoa, M. R. (2008). Student satisfaction and service quality: any differences in demographic factors. International Business Research, 1(4), 131143.

Joseph, M., Yakhou, M. ve Stone, G. (2005). An educational institution's quest for service quality: customers'perspective. Quality Assurance in Education, 13(1), 66-82.

Kaur, H. ve Bhalla, G. S. (2018). Demographic factors in the evaluation of students' satisfaction towards quality in higher education: a study of government colleges of Punjab (India). Management and Labour Studies, 43(4), 234-246.

Kaya, İ. ve Engin, O. (2007). Yükseköğretimde kaliteyi iyileştirme sürecinde öğrenci memnuniyetinin ölçülmesine yönelik bir araştırma. Milli Ĕ̌itim Dergisi, 174, 106-115.

King, M. C. (1993). Advising models and delivery systems. In King, M.C. (Ed.). Academic advising: Organizing and delivering services for student success (pp. 47-54), San Francisco: Jossey-Bass.

Kline, R. B. (2005). Principles and practice of structural equation modeling (2nd Ed.). New York: Guilford Press.

Koçoğlu, C. (2018). Turizm eğitimi veren yükseköğretim kurumlarının itibar bileşenlerinin öğrencilerin memnuniyeti ve tavsiye etme davranışı üzerindeki etkisi. Eskişehir Osmangazi Üniversitesi Iktisadi ve İdari Bilimler Dergisi, 13(2), 23-44.

Kuh, G. ve Hu, S. (2001). The effects of student-faculty interaction in the 1990s. Review of Higher Education, 24(3), 309-332.

Kwek, C.L., Lau, T.C. ve Tan, H.P. (2010). Education quality process model and its influence on students' perceived service quality. International Journal of Business and Management, 5(8), 154-165.

Lagrosen, S., Seyyed-Hashemi, R. ve Leitner, M. (2004). Examination of the dimensions of quality in higher education. Quality Assurance in Education, 12(2), 61-69.

Marshall, S. J. (2018). Internal and external stakeholders in higher education. In Shaping the University of the Future (pp. 77-102). Singapore: Springer.

Marzo-Navarro, M., Pedraja-Iglesias, M. ve Rivera-Torres, M.P. (2005). Measuring customer satisfaction in summer courses. Quality Assurance in Education, 13(1), 53-65. 
McCuddy, M.K., Pinar, M. ve Gingerich, E.F.R. (2008). Using student feedback in designing studentfocused curricula. International Journal of Educational Management, 22(7), 611-37.

Mcdonald, R. P. ve Ho, M-H. R. (2002). Principles and practice in reporting structural equation analyses. Psychological Methods, 7, 64-82.

Mertler, C.A. ve Vannatta, R.A. (2005). Advanced and multivariate statistical methods: practical application and interpretation (Third Edition). CA: Pyrczak Publishing.

Musial, K. (2010). Redefining external stakeholders in Nordic higher education. Tertiary Education and Management, 16(1), 45-60.

O’Neill, M.A. ve Palmer, A. (2004). Importance-performance analysis: a useful tool for directing continuous quality improvement in higher education. Quality Assurance in Education, 1(1), 3952.

Oliver, R. (1999). Whence consumer loyalty? Journal of Marketing, 63, 33-44. doi:10.2307/1252099

Özcan, K. (2013). Üniversitedeki lisans öğrencilerinin öğretimin kalitesine ilişkin algıları. Ĕ̆itim ve Bilim, 38(169), 142-158.

Özdemir, M. (2012). Üniversite öğrencilerinin okul yaşamının niteliğine ilişkin algılarının cinsiyet ve fakülte değişkenlerine göre incelenmesi. Kuram ve Uygulamada Eğitim Yönetimi, 18(2), 225242.

Özdemir, S., Kılınç, A.Ç., Öğdem, Z. ve Er, E. (2013) Eğitim fakültesi öğrencilerinin fakülte yaşamının niteliğine ilişkin memnuniyet düzeylerinin çeşitli değişkenler açısından incelenmesi. Yükseköğretim ve Bilim Dergisi, 3(3), 228-235.

Palli, J.G. ve Mamilla, R. (2012). Students' opinions of service quality in the field of higher education. Creative Education, 3(4), 430-438.

Peker, Ö. (1994). Toplam kalite yönetiminin eğitim sistemine uygulanabilirliği. Amme İdaresi Dergisi, 27(2), 63-78.

Penny, A. R. (2003). Changing the agenda for research into students' views about university teaching: four shortcomings of SRT research. Teaching in Higher Education, 8(3), 399-411.

Popli, S. (2005). Ensuring customer delight: a quality approach to excellence in management education. Quality in Higher Education, 11(1), 17-24.

Pozo-Munoz, C., Rebolloso-Pacheco, E. ve Fernandez-Ramirez, B. (2000). The 'ideal teacher'. implications for student evaluation of teacher effectiveness. Assessment ve Evaluation in Higher Education, 25(3), 253-63.

Rienzi, B.M., Allen, M.J., Sarmiento, Y.Q. ve McMillin, J.D. (1993). Alumni perception of the impact of gender on their university experience. Journal of College Student Development, 34(2), 154-157.

Sakthivel, P.B., Rajendran, G. ve Raju, R. (2005). TQM implementation and students' satisfaction of academic performance. The TQM Magazine, 17(6), 573-89.

Sayeda, B., Rajendran, C. ve Lokachari, P.S. (2010). An empirical study of total quality management in engineering educational institutions of India: perspective of management. Benchmarking: An International Journal, 17(5), 728-67.

Sproule, R. (2000). Student evaluations of teaching: a methodological critique of conventional practices. Education Policy Analysis Archives, 8, 125-142.

Şahin, A. E. (2009). Eğitim fakültesinde hizmet kalitesinin eğitim fakültesi öğrenci memnuniyet ölçeği(ef-ömö) ile değerlendirilmesi. Hacettepe Üniversitesi Eğitim Fakültesi, 37, 106-122.

Şara, P. ve Kocabaş, A. (2012). Sınıf öğretmeni adaylarının sınıf öğretmenliğini tercih nedenleri ve aldıkları eğitimle ilgili görüşleri. Turkish International Journal of Special Education and Guidance \& Counceling, 1(2), 8-17.

Şimşek, Ö. F. (2007). Yapısal eşitlik modellemesine giriş: temel ilkeler ve LISREL uygulamaları. Ankara: Ekinoks Yayınları.

Tabachnick, B.G. ve Fidell, L.S. (2013). Using multivariate statistics (Sixth Ed.). Boston: Pearson. 
Tatlı Haliloğlu, Z., Kokoç, M. ve Karal, H. (2011). Satisfaction state of computer education and instructional technologies students: Karadeniz Technical University case. Elementary Education Online, 10(3), 836-849.

Trivellas, P. ve Geraki, A. (2008). Investigating principals' leadership profile in secondary education, Proceedings of ICMMS 2008 International Conference on Management \& Marketing Sciences, pp. 599-602, ISBN 13 978-1-84816-509-0, Imperial College Press Conference Proceedings, Athens, Greece, May 23-25.

Tsinidou, M., Gerogiannis, V. ve Fitsilis, P. (2010). Evaluation of the factors that determine quality in higher education: an empirical study. Quality Assurance in Education, 18(3), 227-244.

Umbach, P. D. ve Porter, S. R. (2002). How do academic departments impact student satisfaction?: understanding the contextual effects of departments. Research in Higher Education, 43(2), 209234.

Uzgören, N. ve Uzgören, E. (2007). Dumlupınar Üniversitesi lisans öğrencilerinin memnuniyetini etkileyen bireysel özelliklerin istatistiksel analizi-hipotez testi, ki-kare testi ve doğrusal olasılık modeli. Dumlupınar Üniversitesi Sosyal Bilimler Dergisi, 17, 173-193.

Voss, R. ve Gruber, T. (2006). The desired teaching qualities of lecturers in higher education: a means end analysis. Quality Assurance in Education, 14(3), 217-242.

Wachtel, H. K. (1998). Student evaluation of college teaching effectiveness: a brief review. Assessment and Evaluation in Higher Education, 23, 191-212.

Wiers-Jenssen, J., Stensaker, B. ve Grøgaard, J. B. (2002). Student satisfaction: towards an empirical deconstruction of the concept. Quality in Higher Education, 8(2), 183-195.

Yıldız, S. ve Gizir, S. (2018). Öğretim üyelerinin üniversite, akademisyenlik ve bilimsel araştırma kavramlarına ilişkin algılarının metaforlar aracılığıyla incelenmesi. Hacettepe Üniversitesi Ĕ̈itim Fakültesi Dergisi, 33(3), 743-762.

Yükseköğretim Kalite Güvencesi Yönetmeliği. (2015, 23 Temmuz). Resmi Gazete (Sayı: 29423). Erişim adresi:http://www.resmigazete.gov.tr/eskiler/2015/07/20150723-3.htm 


\section{Extended Abstract}

\section{Introduction}

Since the students are the direct recipients of the educational services offered by the universities, the evaluations they make are one of the sources of information that provide useful feedback to the quality improvement activities. In particular, the determination of the level of student satisfaction provides valid and reliable information that shows the quality level of the services offered by the university to its students. In addition, in today's world in which global competition is increasing, universities which aim to be at the top of the most successful university rankings can prove their institutional effectiveness and efficiency based on the information they have obtained about student satisfaction. This situation, which in recent years has accelerated the development of quality, is also believed to be applicable to higher education institutions in Turkey. The faculties of education aiming to train qualified teachers are taking steps to continuously improve the quality of the services and teaching programs they offer. The aim of this study, which is thought to contribute to the quality improvement activities of the faculty and university administration, is to investigate the satisfaction levels of the pre-service teachers in the Education Faculty of Mersin University. Answers to the following research questions were sought:

1. What is the pre-service teachers' level of satisfaction with the service quality in the education faculty?

2. What are the pre-service teachers' levels of satisfaction with a) faculty members, b) counseling, c) faculty and department management, d) the physical facilities, e) technological facilities and (f) courses and schedules in the education faculty?

3. Do the pre-service teachers' levels of satisfaction with the quality of service in the education faculty differ according to their genders?

4. Do the pre-service teachers' levels of satisfaction with the quality of service in the education faculty differ according to their departments?

\section{Method}

This study was carried out in the survey model. The study group was determined by using the convenience sampling method, which gave speed and practicality to the research. The population of the study was all the pre-service teachers who were studying in different departments in the Education Faculty of Mersin University during the fall and spring semester of 2016-2017 academic year. The sample consisted of 674 pre-service teachers from this population. 208 of the pre-service teachers were male $(30,90 \%)$ and 466 were female $(69,10 \%)$. The pre-service teachers were enrolled in eight different departments: Computer Education and Instructional Technology Teaching (CEIT) (3.90\%), Elementary Mathematics Teaching (16.60\%), English Language Teaching (23.10\%), Guidance and Psychological Counseling (14.80\%), Pre-School Teaching (6.20\%), Primary School Teaching (11.60\%), Science Teaching $(11.30 \%)$ and Turkish Teaching (12.50\%). In the collection of data, 'Satisfaction Scale of Students in the Education Faculty' which was developed by Şahin (2009) was used. The internal consistency coefficients were calculated as 0.96 for the whole scale, 0.91 for faculty members, 
0.86 for counseling, 0.83 for faculty and department management, 0.87 for physical facilities, 0.79 for technological facilities and 0.86 for courses and course schedules.

\section{Results and Discussion}

According to the results of the analyses, it was shown that pre-service teachers' satisfaction with the quality of service offered at the education faculty were in general at the intermediate level. More specifically, the pre-service teachers were found to be satisfied at an intermediate level with the courses and course schedules, faculty members, counseling, faculty and department management, physical and technological facilities. The results indicated that there were statistically significant differences between female and male pre-service teachers' satisfaction with faculty members, faculty and department management, the physical and technological facilities. When the satisfaction levels were examined in terms of departments, it was found that the most satisfied pre-service teachers were from the departments of CEIT and Turkish Language Teaching whereas the least satisfied pre-service teachers were from the departments of Preschool and Primary School Teaching. The satisfaction levels of pre-service teachers from the departments of English Language Teaching, Science Teaching, Elementary Mathematics Teaching and Guidance and Psychological Counseling were not statistically significantly different. The students' satisfactions with the services they receive at their universities will undoubtedly contribute to their educational lives and academic achievements. If the students' level of satisfaction with the services offered at the university is accepted as an indicator of the quality of life at the university, the efforts to strengthen weaknesses of an institution will not only enable students to be satisfied with the education services they receive but also help universities increase their quality. Based on the results of this study, some suggestions for education faculties to implement may be presented. For instance, education faculties can involve all internal and external stakeholders, including pre-services teachers, in the evaluation process in order to ensure that the quality of service provided can be determined and evaluated in a multi-perspective and realistic way. In addition, it may be suggested that these quality determination and evaluation studies should be regularly planned and implemented at least once in an academic term or a year. Thus, a great variety of information and data related to the service quality of the faculties can be gathered and necessary efforts for quality improvement can be directed in the required areas through quality assurance systems. Some suggestions for future research may also be presented. In terms of generalizability of the results of this study, a similar study can be done with a larger sample of approximately similar number of female and male pre-service teachers who can represent all departments and classes in the faculty. In order to obtain more diverse and detailed information about the service quality of the faculty of education, longitudinal research can be conducted involving all internal and external stakeholders of the faculty in the evaluation process. Further in-depth research and interviews can be conducted to determine whether there are other factors affecting the pre-service teachers' satisfaction with service quality. Finally, considering the absenteeism status of pre-service teachers evaluating the service quality of the faculty of education may increase the reliability and validity of the studies to be conducted and the conclusions to be reached. 